\title{
Re-working biographies: Women's narratives of pregnancy whilst living with epilepsy
}

, Dr.Annalise Weckesser, Research Fellow*

annalise.weckesser@bcu.ac.uk

Prof.Elaine Denny, Professor Emeritus

elaine.denny@bcu.ac.k

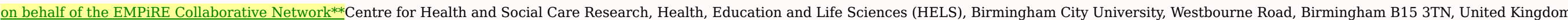

${ }^{*}$ Corresponding author.

Abstract

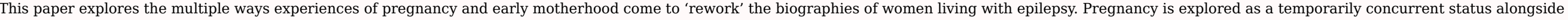

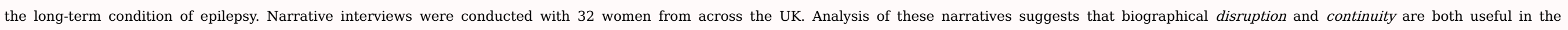

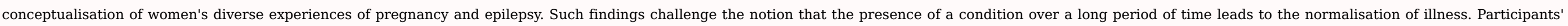

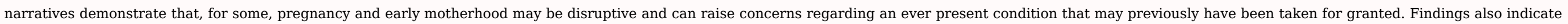
the need for a greater consideration of gender and care responsibilities, as well explorations of concomitant conditions, in the theorising of biographies and chronic illness.

Keywords: United Kingdom; Gender; Biographical disruption \& continuity; Pregnancy; Reproductive health; Epilepsy

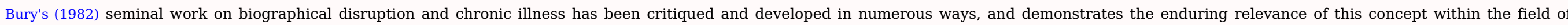

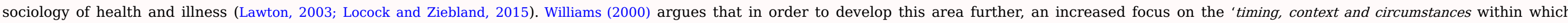

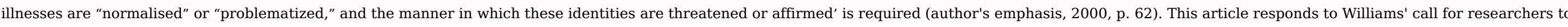

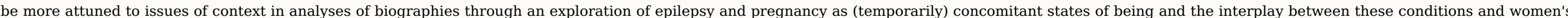

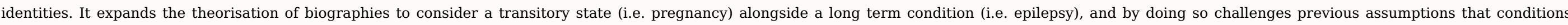

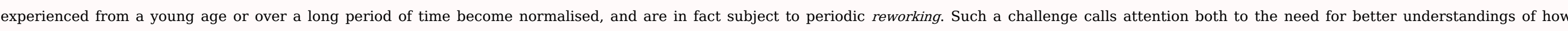

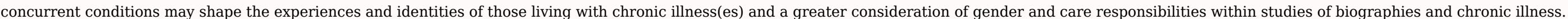

\section{Literature review}

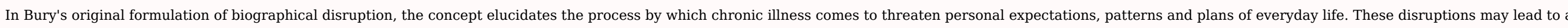

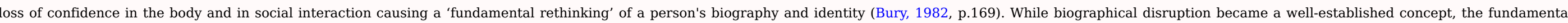

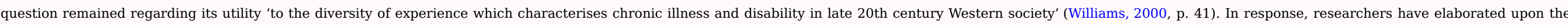

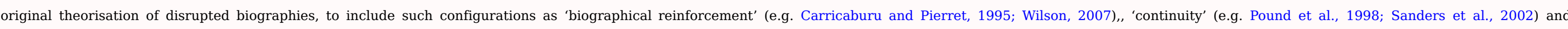

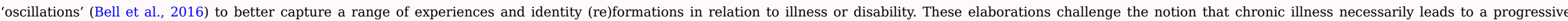

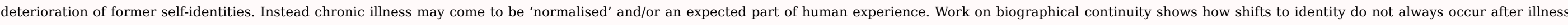

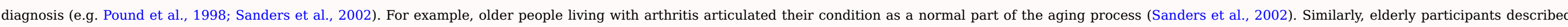
their experience of stroke as 'not that bad' and to be expected as one ages, challenging popular conceptions that strokes 'shatter lives' (Pound et al., 1998).

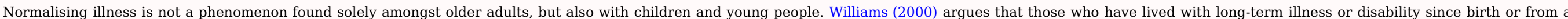




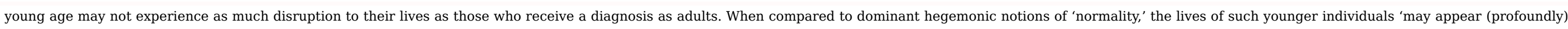

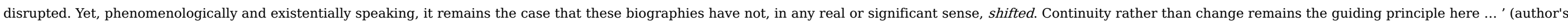

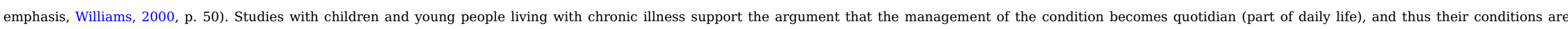

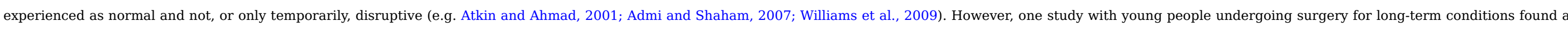
wide range of biographical experiences, with disruptions associated with their surgery, the ongoing management of their condition and the transition from adolescence to adulthood (Bray et al., 2014).

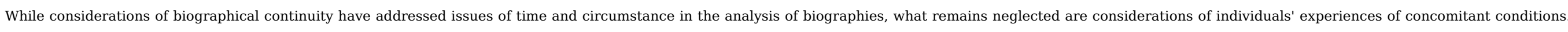

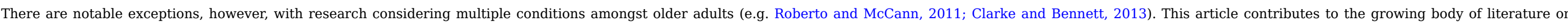

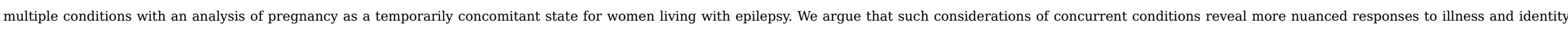

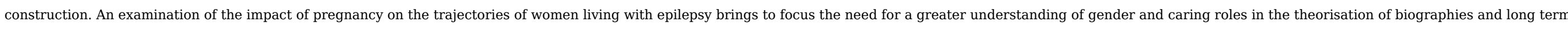



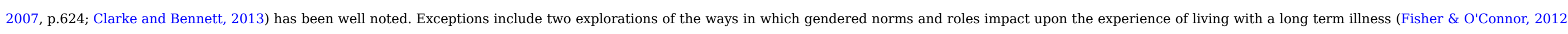

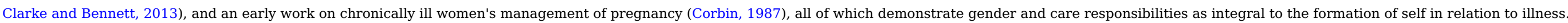

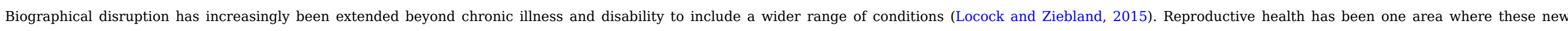

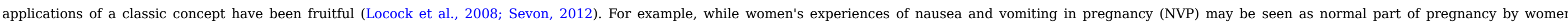

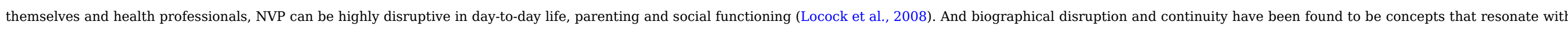

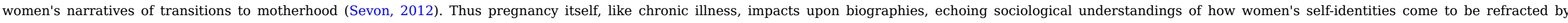
transitions to motherhood (Bailey, 1999).

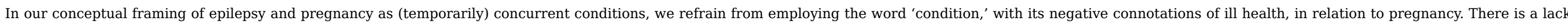

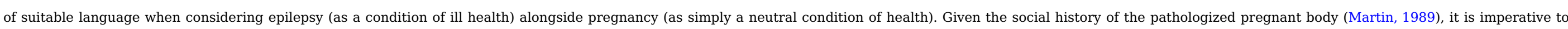
stress that pregnancy is not considered here as a state of poor health, but of altered health. Thus, in lieu of the term 'condition' we employ the terms 'state' or 'status' of health in reference to pregnancy.

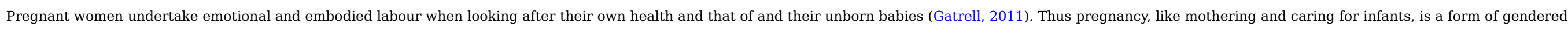

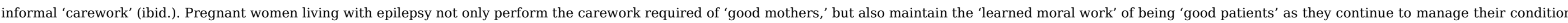

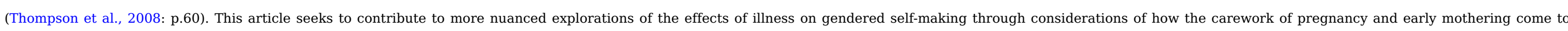
intersect with the (moral) work of managing epilepsy.

\section{Methodology}

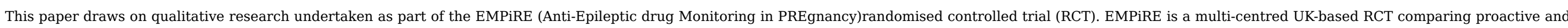

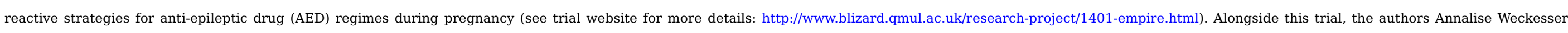

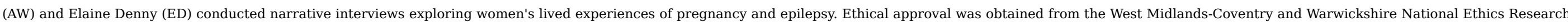

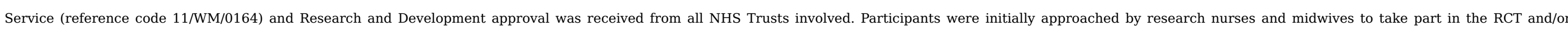

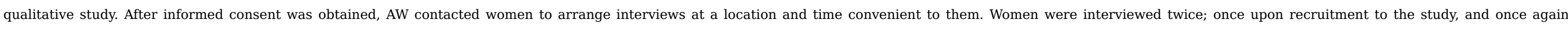

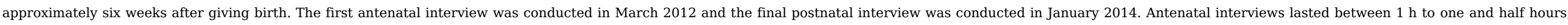

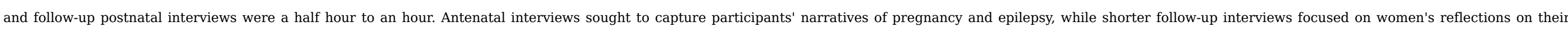
pregnancy and epilepsy management, as well as their experiences of giving birth and early motherhood.

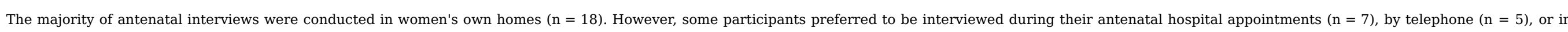

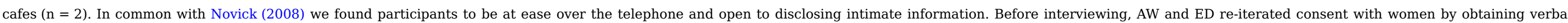




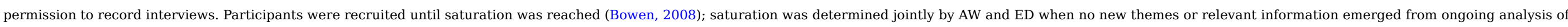

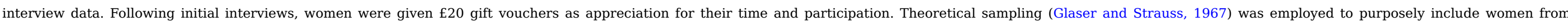

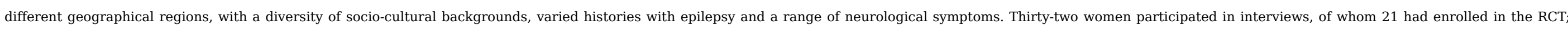

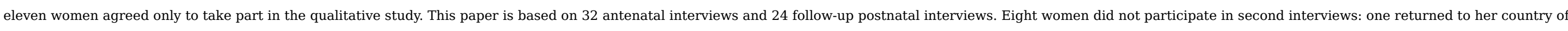

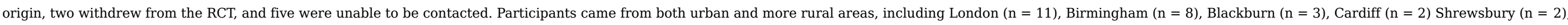
Sheffield $(n=2)$, Liverpool $(n=1)$, Stafford $(n=1)$, Gwent $(n=1)$ and Worcestershire $(n=1)$.

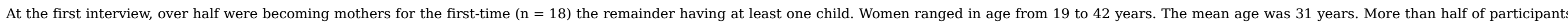

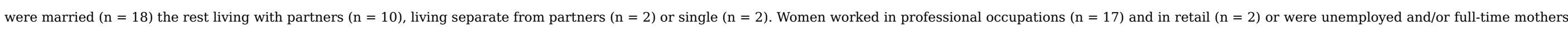

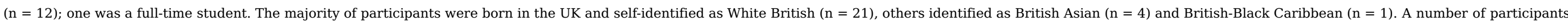
had immigrated to the UK, including three who identified as White European, and one each as Chinese, Black African, and White American.

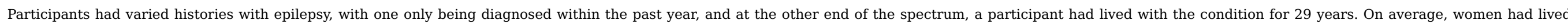

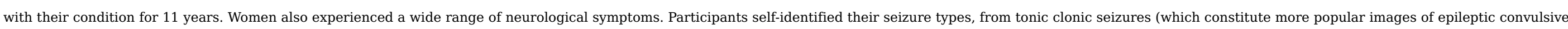

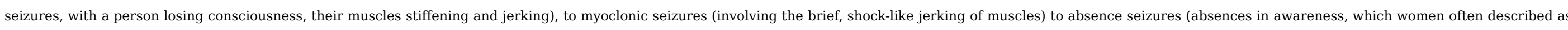

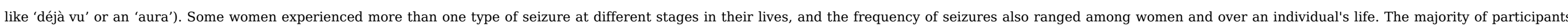

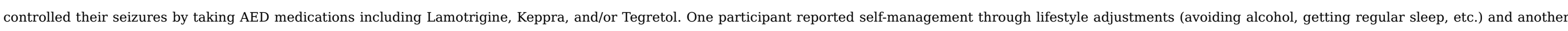
had only been recently diagnosed with epilepsy and was not yet on medication.

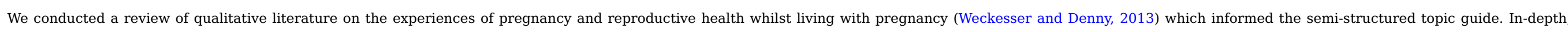

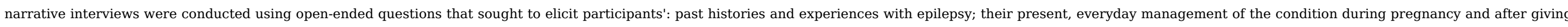

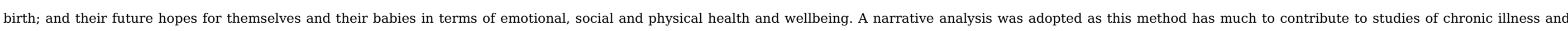

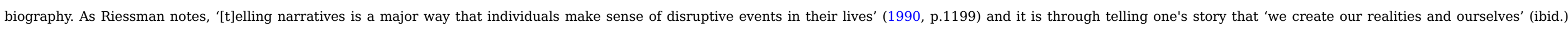

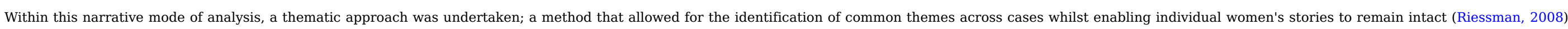

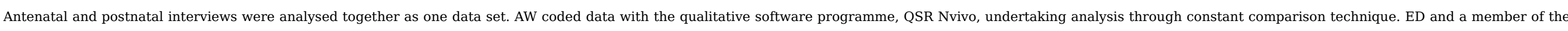
trial team checked this analysis by independently coding a portion of interview data. These analyses were brought together to identify common and overlooked themes as well as deviant cases.

\section{Findings: women's re-worked biographies}

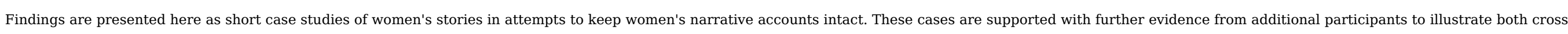

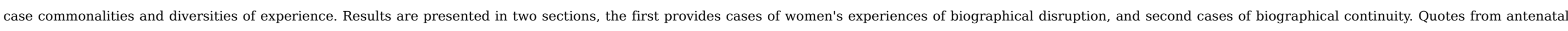
interviews are indicated with the initials 'AI' and postnatal interviews with 'PI.'

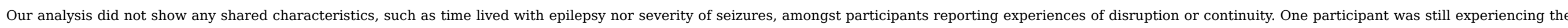

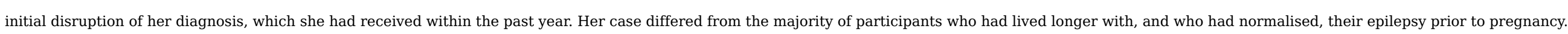

\subsection{Section 1: cases of disruption in pregnancy, seizure \& early parenthood}

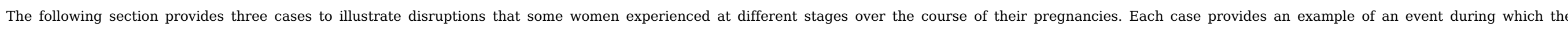

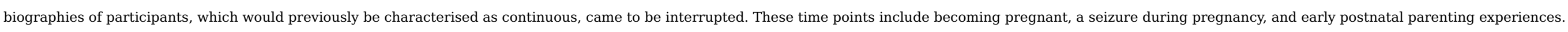

\subsubsection{Disruption at pre-conception \& becoming pregnant}

Riva (all participants have been given pseudonyms) has lived with and managed her epilepsy for nearly twenty years. When reflecting upon how her epilepsy affects her day-to-day life she stated: 


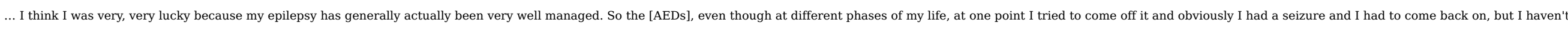
had like that many seizures in my whole life. So it was, it was very well managed, so I think before I started getting pregnant, you just mentally assume you're pretty much normal ... (AI)

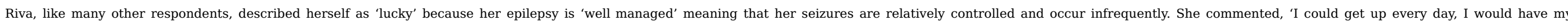

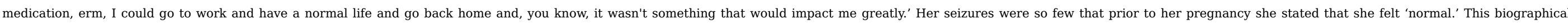

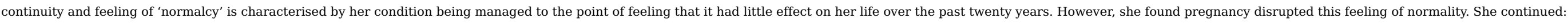

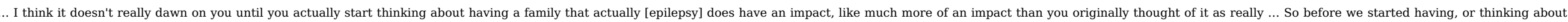

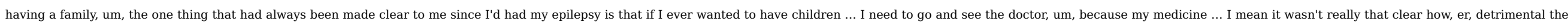
medicine was [to the fetus] ...

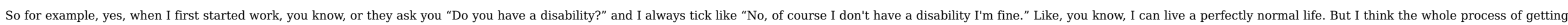
pregnant and now being pregnant has kind of made me realise that actually that's not really quite the case as I initially thought ...

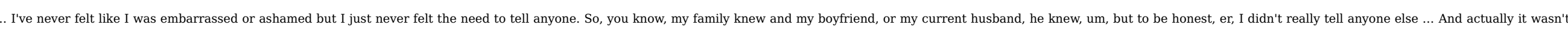
sort of until I was in the process of trying to get pregnant that actually I thought "you know what I need to tell my boss," yes my boss needs to know, if something happens to me in the office ... (AI)

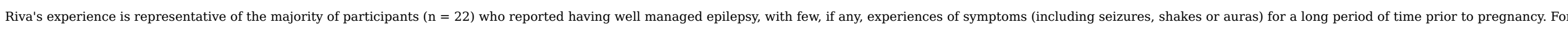

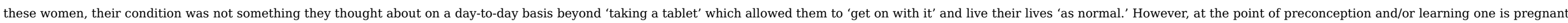

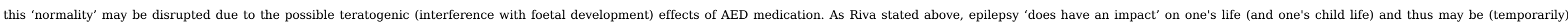

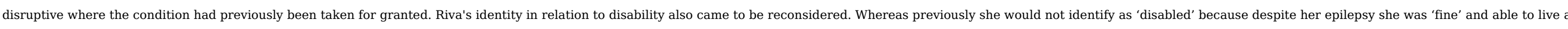

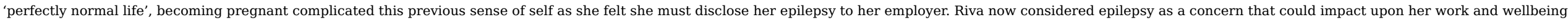

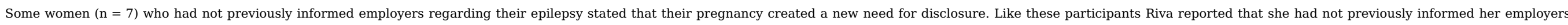

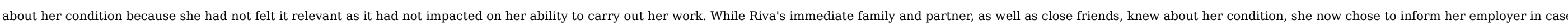

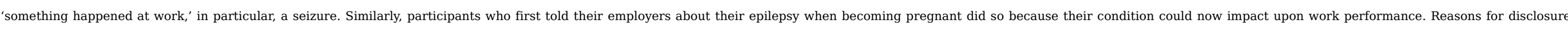

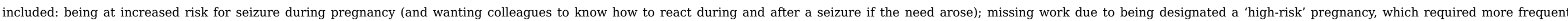

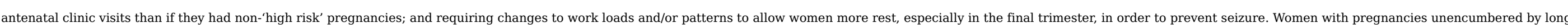

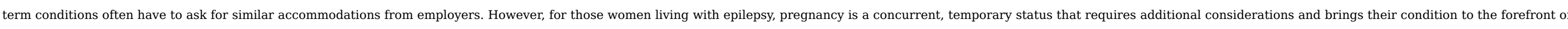
their minds when it had previously been something that had not impacted upon their day to day life.

\subsubsection{Disruption from pregnancy-induced seizure}



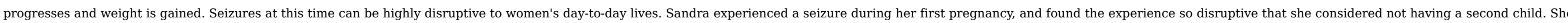
was diagnosed eighteen years ago, prior to her first pregnancy, and considered her epilepsy well managed. Sandra talked about the experience of having a seizure in her first pregnancy:

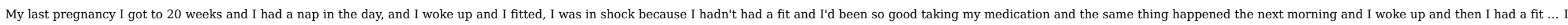

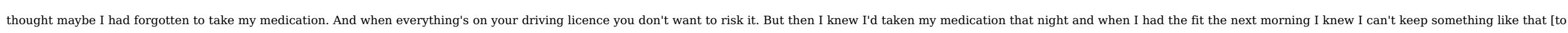
myself], I have to do something ... (AI)

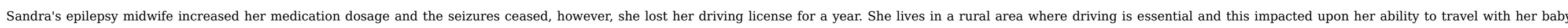

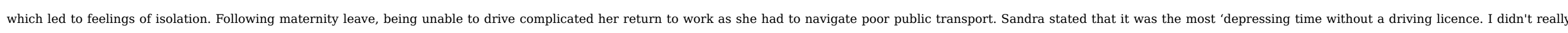

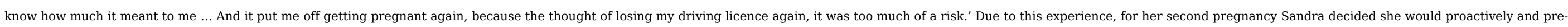




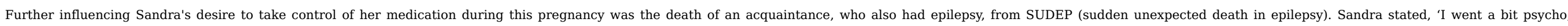

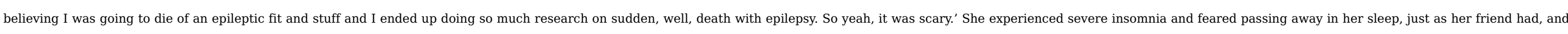
worried about not being there for her husband and children.

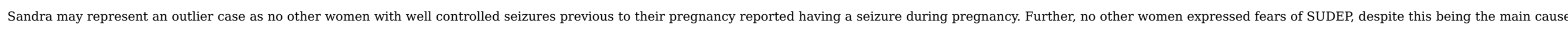

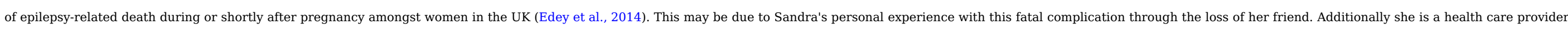
and thus may have more access to information regarding the risk of SUDEP during pregnancy.

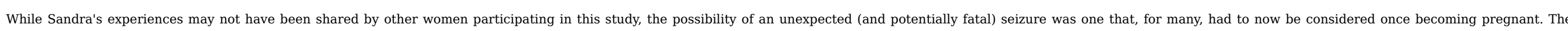

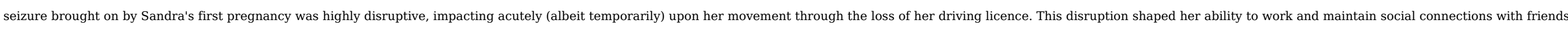

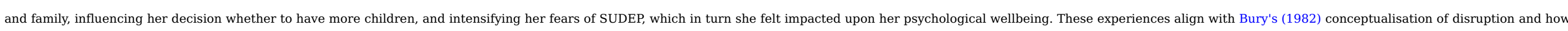

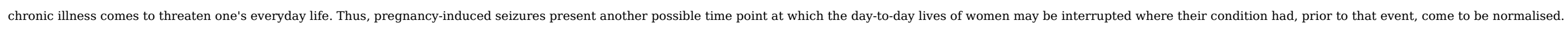

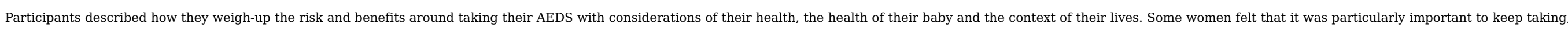

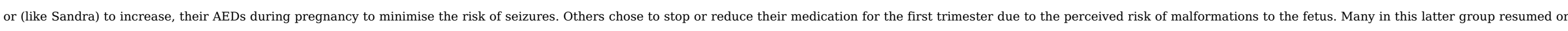

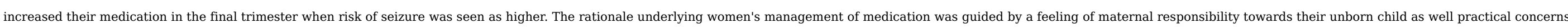
of needing to remain seizure-free in order to better care for their baby.

\subsubsection{Disruption in early mothering}

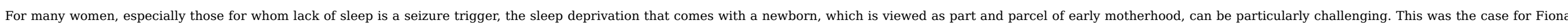
who had a prolonged, week-long labour during which she had little sleep, and who then describes further sleep deprivation during her first few weeks after returning home from hospital with her baby:

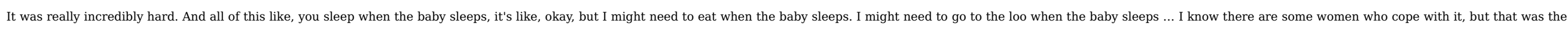
worst thing for me, the sleep, by a million miles. (PI)

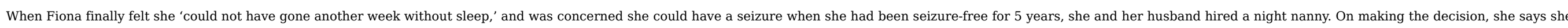
thought

I can't leave [the baby] with somebody else and oh, I can't do that, and overnight, and that's so bad and ... you know.

[Interviewer: Why did you think it was bad?]

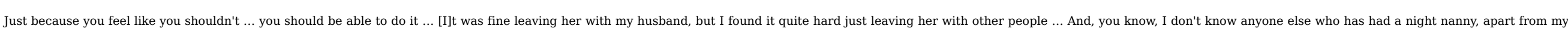
sister, so you're kind of like, oh God ... I felt like I should be fine with this, I should be able to do it ... (PI)

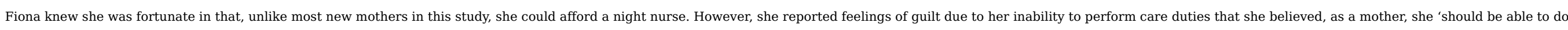
and that most women must manage alone. Here, her epilepsy and the potential seizures brought on by sleep deprivation disrupted her notion of what she 'should' be able to do as a mother.

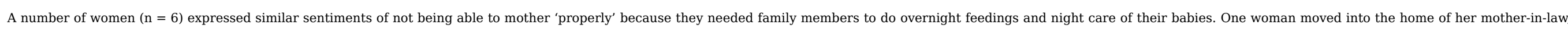

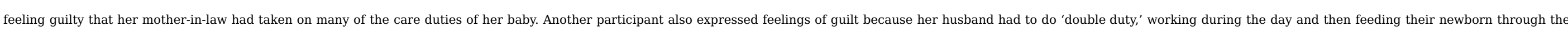

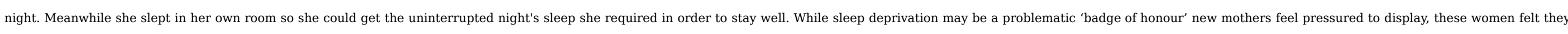

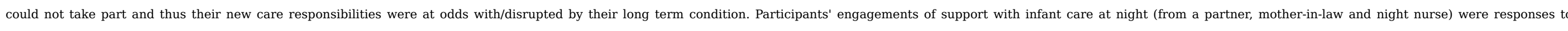

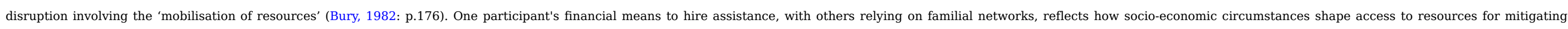




\subsection{Section 2: cases of continuity: 'It's twaddle really'}

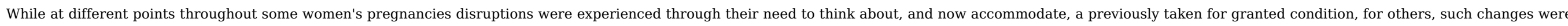

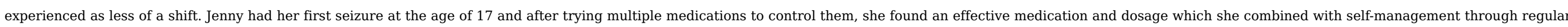

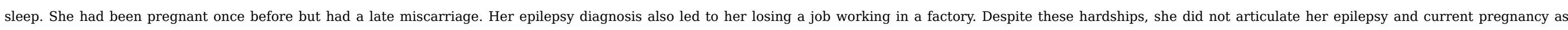
disruptive factors in her life.

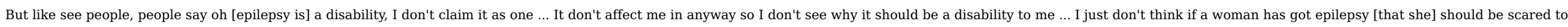

have a baby because she could be like me, everything is fine, no worries at all. So I wouldn't even worry about thinking, "Oh I can't have a baby because I've got epilepsy," because it's twaddle really. (AI)

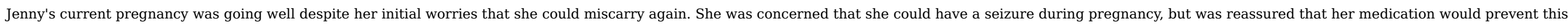

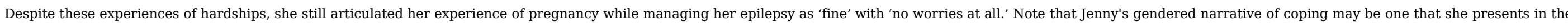

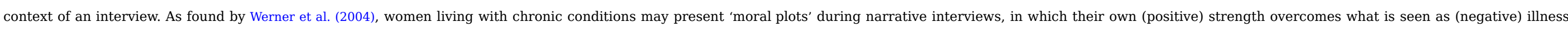
talk (i.e. complaining).

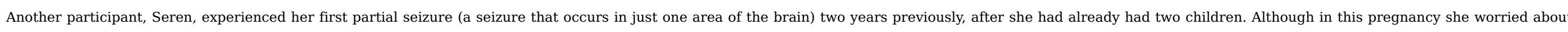

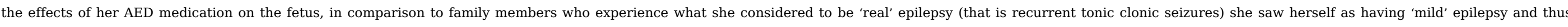

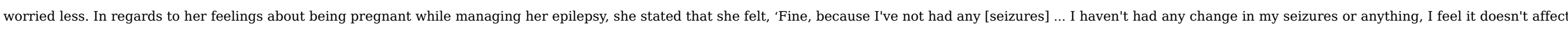

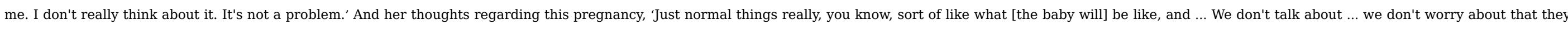
might have my epilepsy or anything, just the normal what he'll look like, and you know.'

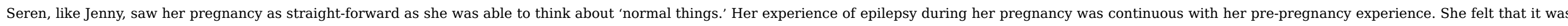
a more 'mild' and controlled condition than those of her siblings and thus one she said that does not affect her and 'is not a problem' in her everyday life.

\subsubsection{Continuity in early motherhood}

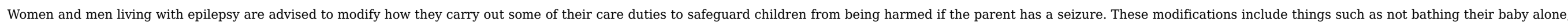

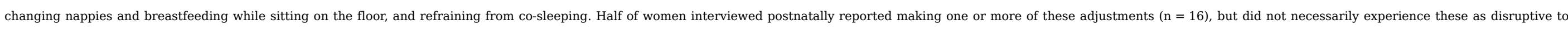
their ability to care for their newborns.

Simone responded to whether she has had to modify how she cares for her baby because of her condition

I do think, I don't do any co-sleeping ..., and my partner does the bathing every night really, not because I don't want to, I mean that's the only time he gets to spend with [our baby] really because he's at work all day so it's quite good for him.

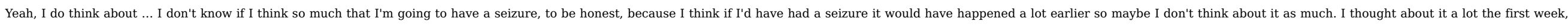

maybe two weeks, and now not anymore, not anymore. But I don't bathe him when I'm alone.

Maybe I wouldn't have done [co-sleeping] anyway, I'm not sure, I probably would have read more into it, I've just decided not to do it, but I probably would have read more about it. (PI)

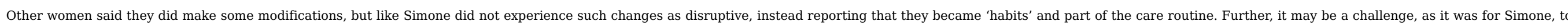
disentangle what care choices one makes to accommodate epilepsy and what one would do regardless of the condition.

\section{Discussion}

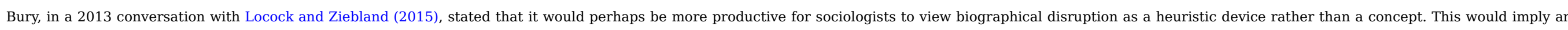




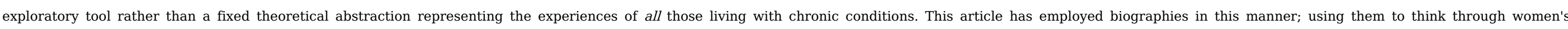
experiences of pregnancy and early motherhood whilst managing their epilepsy. Doing so reveals that women undertake a re-working of their identities during this transitional time in their lives.

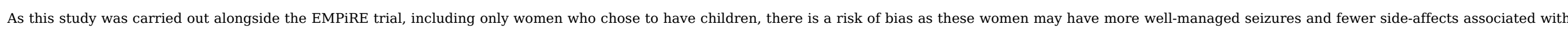

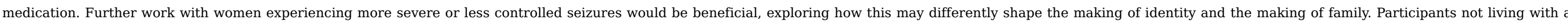

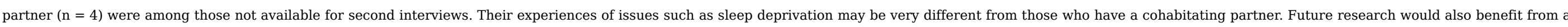



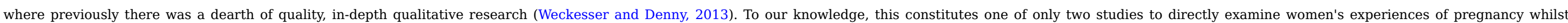
managing epilepsy, the first being that of Thompson et al. (2008)

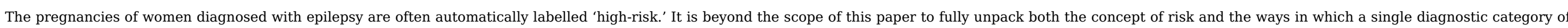

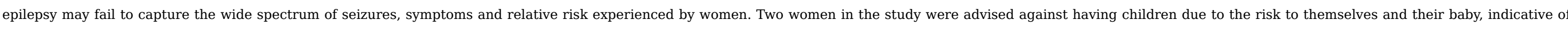

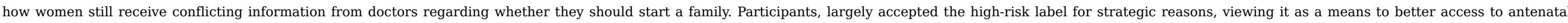
services, which offered a sense of security

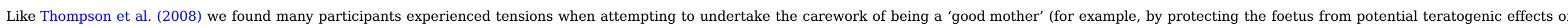

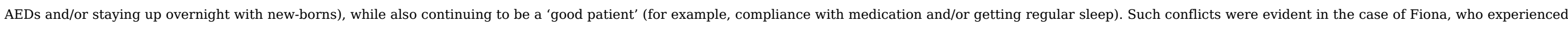

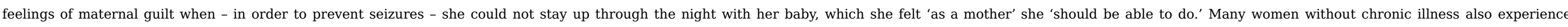

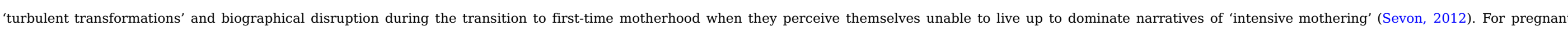

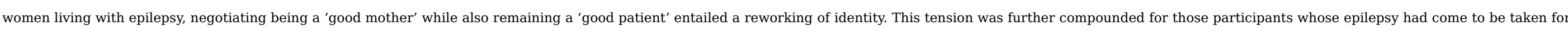
granted prior to pregnancy.

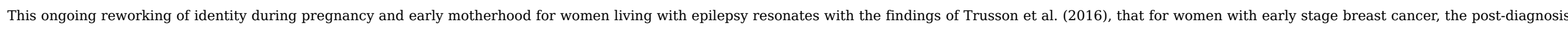

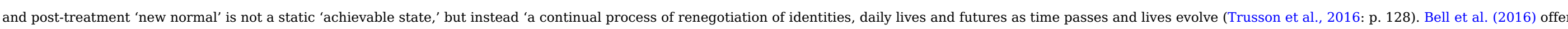

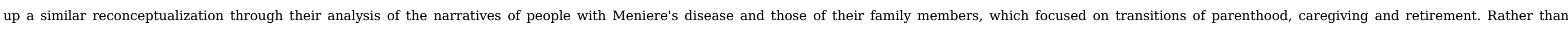

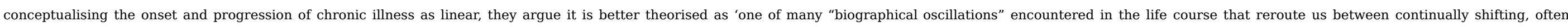

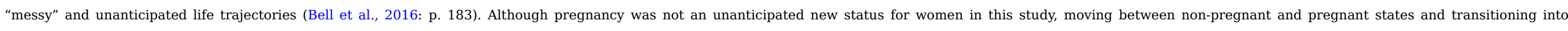
motherhood and new care roles may also be conceptualised as 'oscillations' with ongoing reworkings of identity, rather than as a form of linear progression through a temporary disruption.

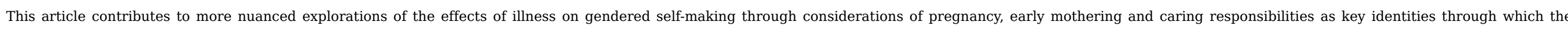

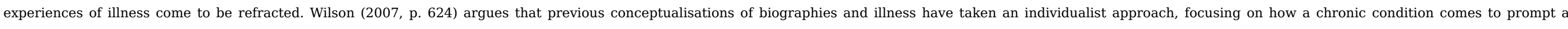

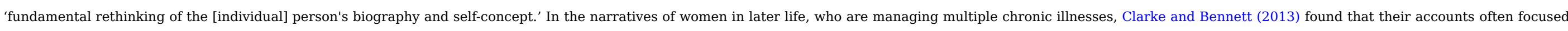

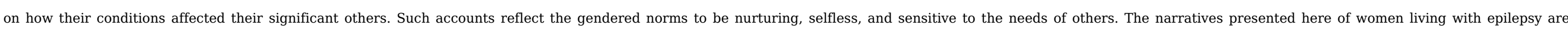

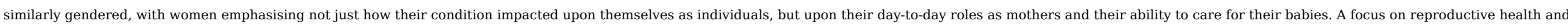
motherhood revealed less individualistic and more contextualised biographies.

\section{Conclusion}

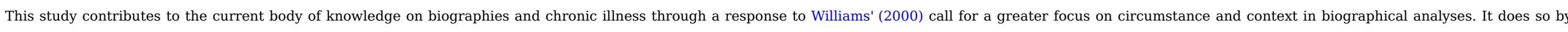

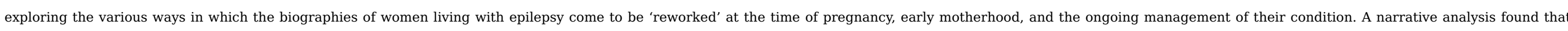

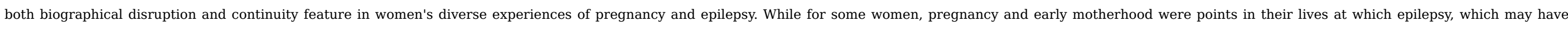
previously been taken for granted and normalised, came to be problematized; for others, such changes were experienced as less of a shift. 


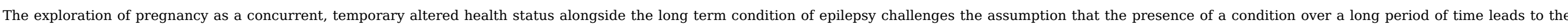

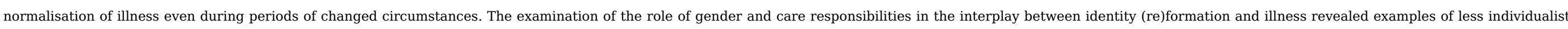

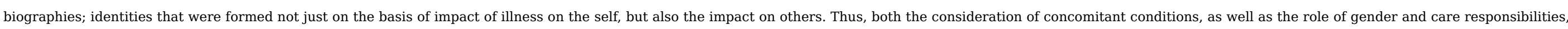
opens up and expands understandings of the diversity of biographies.

\title{
Uncited references
}

\author{
Bury, 2001.
}

\section{Acknowledgements}

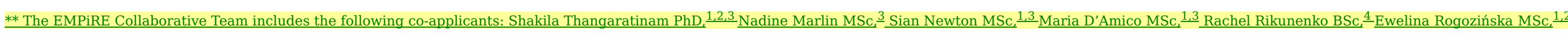

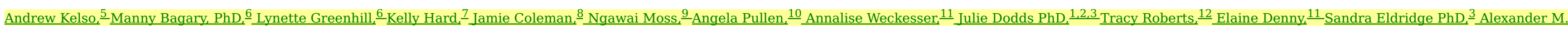

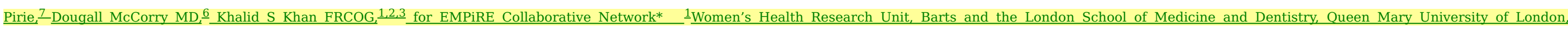

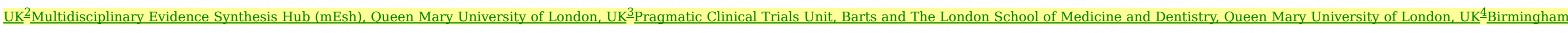

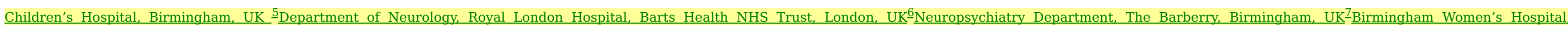

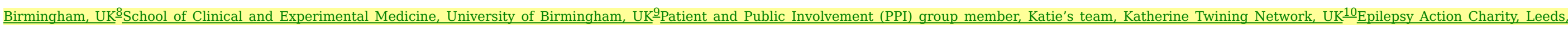
$\underline{\mathrm{UK}}^{11}$ Centre for Health and Social Care Research, Birmingham City University, UK $\underline{12}$ Health Economics Unit, University of Birmingham, UK

and the following collaborators: Lee Middleton -

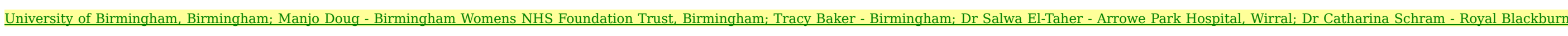

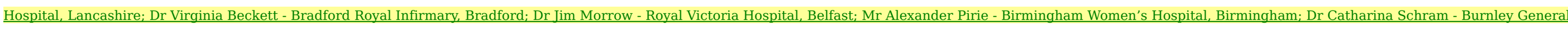

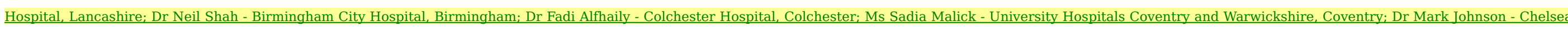

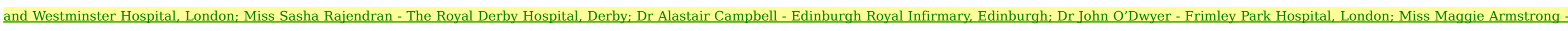

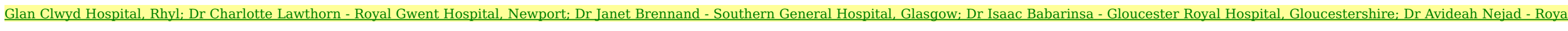

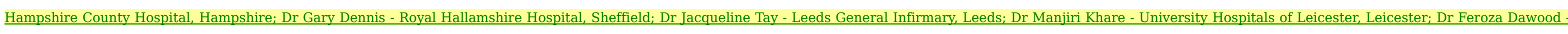

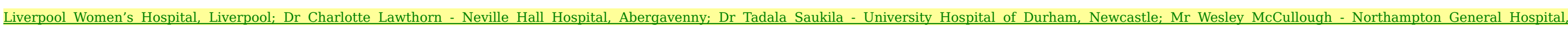

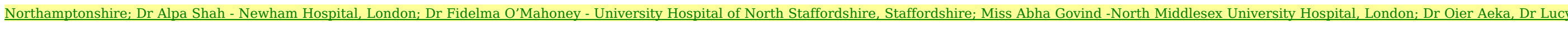

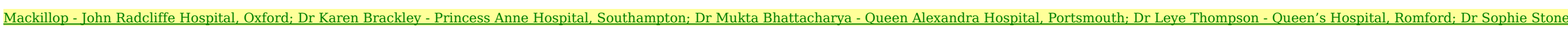

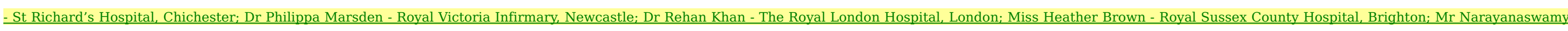

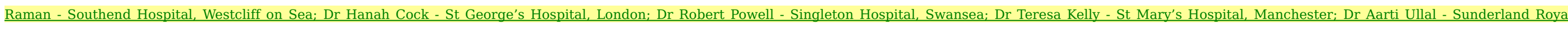

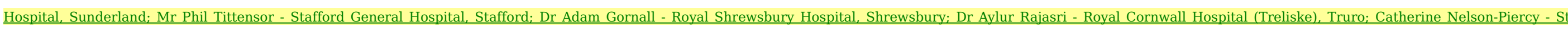

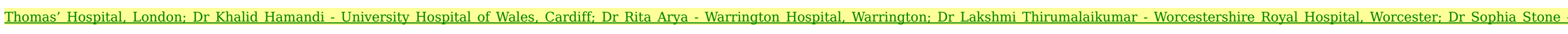

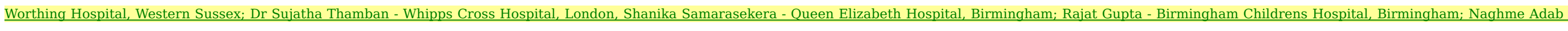

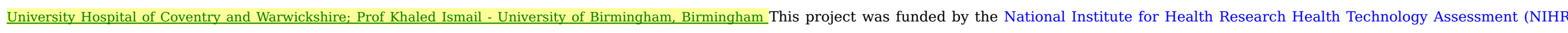

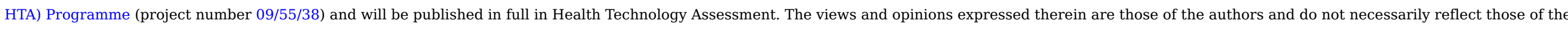
HTA programme, NIHR, National Health Service (NHS) or the Department of Health.

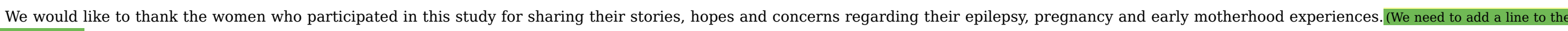

\section{References}

Adab N. and Chadwick D.W., Management of women with epilepsy during pregnancy, Obstetrician Gynaecol. 8, 2006, 20-25. 
Admi H. and Shaham B., Living with epilepsy: ordinary people coping with extraordinary situations, Qual. Health Res. 17 (9), $2007,1178-1187$.

Atkin K. and Ahmad W., Living a normal life: young people with thalassaemia major or sickle cell disorder, Soc. Sci. Med. 53, 2001, 615-626.

Bailey L., Refracted selves? A study of changes in self-identity in the transition to motherhood, Sociology 33 (2), 1999, 335-352.

Bell S.L., Tyrrell J. and Phoenix C., Meniere's disease and biographical disruption: where family transistions collide, Soc. Sci. Med. 166, 2016, 177-185.

Bendelow G.W. and Williams S., Transcending the dualisms: towards a sociology of Pain, Sociol. Health Illn. 17, 1995, 139-165.

Bowen G.A., Naturalistic inquiry and the saturation concept: a research note, Qual. Res. 8 (1), 2008, 137-152.

Bray L., Kirk S. and Callery P., Developing biographies: the experiences of children, young people and their parents of living with a long-term condition, Sociol. Health Illn. 36, 2014, 823-839.

Bury M.R., Chronic illness as biographical disruption, Sociol. Health Illn. 4, 1982, 167-188.

Bury M.R., Illness narratives: fact or fiction?, Sociol. Health Illn. 23 (3), 2001, 263-285.

Carricaburu D. and Pierret J., From biographical disruption to biographical reinforcement: the case of HIV-positive men, Sociol. Health Illn. 17, 1995, 65-88.

Ciambrone D., Illness and other assaults on the self: the relative impact of HIV/AIDS on women's lives, Sociol. Health Illn. 23, 2001, 517-540.

Clarke L.H. and Bennett E., 'You learn to live with all the things that are wrong with you': gender and the experience of multiple chronic conditions in later life, Ageing \& Soc. 33, 2013, 342-360.

Corbin J., Women's perceptions and management of pregnancy complicated by chronic illness, Health Care Women Int. 8, $1987,317-337$.

Edey S., Moran N. and Nashef L., SUDEP and epilepsy-related mortality in pregnancy, Epilepsia 55 (7), 2014, e72-e704.

Fisher C. and O'Connor M., “Motherhood” in context of living with breast cancer, Cancer Nurs. 35 (2), 2012, 157-163.

Gatrell C., Putting pregnancy in its place: conceiving pregnancy as carework in the work place, Health \& Place 17, 2011, 395-402.

Glaser B.G. and Strauss A., The Discovery of Grounded Theory: Strategies for Qualitative Research, 1967, Aldine Pub. Co; Chicago, IL.

Lawton J., Lay experiences of health and illness: past research and future agendas, Sociol. Health \& Illn. 25, 2003, 23-40.

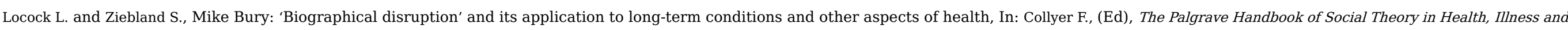

Medicine, 2015, Palgrave Macmillan; London, UK.

Locock L., Alexander J. and Rozmovits L., Women's responses to nausea and vomiting in pregnancy, Midwifery 24, 2008, 143-152.

Martin E., The Woman in the Body, 1989, Open University Press; Milton Keynes, UK.

Novick G., Is there a bias against telephone interviews in qualitative research?, Res. Nurs. Health 31, 2008, 391-398.

Pound P., Gompertz P. and Ebrahim S., Illnes in the context of older age: the case of stroke, Sociol. Health Illn. 20, 1998, 489-506.

Riessman C.K., Strategic use of narrative in the presentation of self and illness: a research note, Soc. Sci. Med. 11, 1990, 1195-1200.

Riessman C.K., Narrative Methods for the Human Sciences, 2008, Sage; Thousand Oaks, CA.

Roberto K. and McCann B., Everyday health and identity management among older women with chronic health conditions, J. Aging Stud. 25, 2011, 94-100.


227-253. 
Sevon E., 'My life has changed, but his life hasn't': making sense of the gendering of parenthood during the transition to motherhood, Fem. Psychol. 22, 2012, 60-80.

Thomas H., Pregnancy, illness and the concept of career, Sociol. Health \& Illn. 25, 2003, 383-407.

Thompson D., Thomas H., Solomon J., Nashef L. and Kendall S., Chronic illness, reproductive health and moral work: women's experiences of epilepsy, Chronic Illn. 4, 2008 , 54-64.

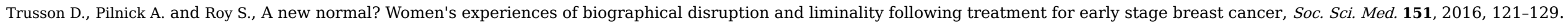

Weckesser A. and Denny E., Women living with epilepsy, experiences of pregnancy and reproductive health, Seizure 22 (2), 2013, 91-98.

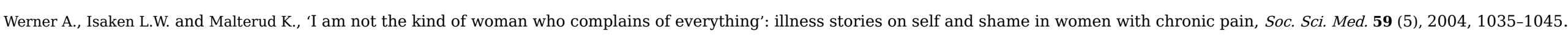

Williams S.J., Chronic illness as biographical disruption or biographical disruption as chronic illness? Reflections on a core concept, Sociol. Health \& Illn. 22, $2000,40-67$.

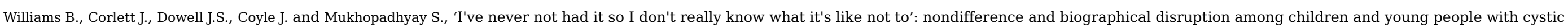
fibrosis, Qual. Health Res. 19, 2009, 1443-1455.

Wilson S., 'When you have children, you're obliged to live': motherhood, chronic illness and biographical disruption, Sociol. Health \& Illn. 29, 2007, 610-626.

\section{Highlights}

- Pregnancy, early motherhood 'rework' the biographies of women living with epilepsy.

- Biographical disruption \& continuity found in narratives of pregnancy \& epilepsy.

- Pregnancy can be disruptive for those living with 'normalised' chronic illness.

- Need for consideration of gender, carework in biographies \& chronic illness studies.

\section{Queries and Answers}

Query: Please check the retained degrees and roles of the authors, and correct if necessary.

Answer: Please change Annalise Weckesser's position - she is now a 'Senior Research Fellow.'

Query: The country name has been inserted for the affiliation. Please check, and correct if necessary.

Answer: this is fine

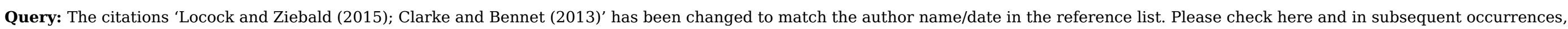
and correct if necessary.

Answer: this is fine

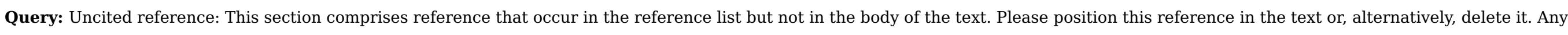
reference not dealt with will be retained in this section. Thank you.

Answer: this is fine

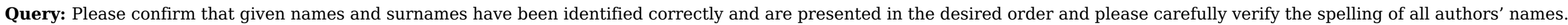

Answer: Yes 

contact r.eyles@elsevier.com immediately prior to returning your corrections.

Answer: Yes 